\title{
Syntheses and Structures of Keggin-Type Polyoxometalate Crystals Hybridized with a Polymerizable Ionic-Liquid
}

\author{
Saki Otobe ${ }^{1}$, Yoshiki Kiyota ${ }^{1}$, Tatsuhiro Kojima ${ }^{2,3}$, Yoshiki Oda ${ }^{4}$, Shinichi Koguchi ${ }^{1}$, \\ Yosuke Okamura $^{5}$, Masashi Higuchi ${ }^{5}$, Masaki Kawano ${ }^{2,6}$, Yu Nagase ${ }^{5}$, and Takeru Ito ${ }^{1 *}$ \\ 1 Department of Chemistry, School of Science, Tokai University, Hiratsuka, Kanagawa 259-1292, Japan \\ 2 Division of Advanced Materials Science, Pohang University of Science and Technology (POSTECH), Pohang 790-784, South \\ Korea \\ 3 Department of Chemistry, Graduate School of Science, Osaka University, Toyonaka, Osaka 560-0043, Japan \\ 4 Technology Joint Management Office, Tokai University, Tokai University, Hiratsuka, Kanagawa 259-1292, Japan \\ 5 Department of Applied Chemistry, School of Engineering, Tokai University, Hiratsuka, Kanagawa 259-1292, Japan \\ 6 Department of Chemistry, Graduate School of Science and Engineering, Tokyo Institute of Technology, Meguro-ku, Tokyo \\ 152-8550, Japan \\ * Corresponding author: e-mail: takeito@keyaki.cc.u-tokai.ac.jp
}

\begin{abstract}
Keggin-type polyoxometalate clusters were successfully hybridized with a polymerizable ionic-liquid having methacryloyl group and imidazolium moieties (denoted as $\mathrm{MAImC}_{1}$ ). Metatungstate $\left(\left[\mathrm{H}_{2} \mathrm{~W}_{12} \mathrm{O}_{40}\right]^{6-}, \mathrm{H}_{2} \mathrm{~W}_{12}\right)$ and dodecamolybdophosphate $\left(\left[\mathrm{PMo}_{12} \mathrm{O}_{40}\right]^{3-}, \mathrm{PMo}_{12}\right)$ anions were firstly employed to obtain inorganic-organic hybrid crystals. Their compositions and structures were clearly revealed by single crystal structure analyses.
\end{abstract}

Key words: Inorganic-organic, Hybrid crystal, Polymerizable, Ionic-liquid, Polyoxometalate

\section{INTRODUCTION}

Ionic-liquids are an attractive class of organic molten electrolytes having characteristic properties such as conductivity, catalysis, and separation abilities [1-8]. The combination of ionic-liquids with other inorganics bringing additional properties can lead to the construction of functional inorganic-organic hybrid materials [9-12]. Polyoxometalate (POM) clusters having several physicochemical properties are promising counter parts [13-24]. Keggin-type POMs have been well-known as catalysts or proton conductors [25-28], and their hybridization with ionic-liquids or polymer matrices has been achieved [29-37].

Such ionic liquid-POM hybrids sometimes have ill-ordered or disordered molecular arrangements in the solid states. This may be disadvantage to exploit their characteristic functions. Recently, we designed a polymerizable ionic-liquid of $\left[\left\{\mathrm{CH}_{2}=\mathrm{C}\left(\mathrm{CH}_{3}\right) \mathrm{COO}\left(\mathrm{CH}_{2}\right)_{2}\right\} \mathrm{C}_{3} \mathrm{H}_{3} \mathrm{~N}_{2}\left(\mathrm{CH}_{3}\right)\right]^{+}$(denoted as $\mathrm{MAImC}_{1}$, Fig. 1a) having imidazolium and methacryloyl group. MAImC 1 can be hybridized with several POMs as single crystals [38-40]. MAImC $1-\mathrm{POM}$ hybrid crystals are well-defined in an atomic level, and polymerizable to obtain conductive hybrid polymers. In these cases, dodecatungstophosphate $\left(\left[\mathrm{PW}_{12} \mathrm{O}_{40}\right]^{3-}, \quad \mathrm{PW}_{12}\right)$ and dodecatungstosilicate $\left(\left[\mathrm{SiW}_{12} \mathrm{O}_{40}\right]^{4-}, \mathrm{SiW}_{12}\right)$ anions were utilized as Keggin-type POMs.

We report here the first syntheses of $\mathrm{MAImC}_{1}$ hybrid crystals with other Keggin-type clusters. Metatungstate $\left(\left[\mathrm{H}_{2} \mathrm{~W}_{12} \mathrm{O}_{40}\right]^{6-}, \quad \mathrm{H}_{2} \mathrm{~W}_{12}, \quad\right.$ Fig. $\left.1 \mathrm{~b}\right) \quad$ and dodecamolybdophosphate $\left(\left[\mathrm{PMo}_{12} \mathrm{O}_{40}\right]^{3-}, \mathrm{PMo}_{12}\right.$, Fig. $\left.1 \mathrm{~b}\right)$ anions were employed. Structures of both hybrid crystals were revealed by single crystal X-ray structure analyses. (a)

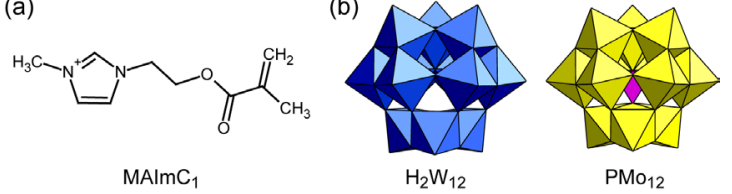

Fig. 1. (a) Molecular structure of MAImC 1 . (b) Molecular structure of metatungstate $\left(\mathrm{H}_{2} \mathrm{~W}_{12}\right.$, left $)$ and dodecamolybdophosphate ( $\mathrm{PMo}_{12}$, right).

\section{EXPERIMENTAL}

2.1 Materials and methods

All chemical reagents were used as received from comercial sources except for polmerizable ionic-liquid imidazolium cation $\left(\mathrm{MAImC}_{1}\right)$. MAImC $\mathrm{I}_{1}$ was obtained as iodide salt according to our previous studies [38-40].

IR spectra (as $\mathrm{KBr}$ pellet) were measured on a Jasco FT/IR-4200ST spectrometer. Powder X-ray diffraction (XRD) patterns were obtained with a Rigaku MiniFlex300 or a Bruker AXS D8 ADVANCE diffractometer $(\mathrm{Cu} \mathrm{K \alpha}$ radiation, $\lambda=1.54056 \AA$ ) at ambient temperature. CHN elemental analyses were performed with a PerkinElmer 2400II elemental analyzer.

\subsection{Synthesis of MAImC $1-\mathrm{H}_{2} \mathrm{~W}_{12}$ hybrid crystal}

Sodium metatungstate $\left(\mathrm{Na}_{6}\left[\mathrm{H}_{2} \mathrm{~W}_{12} \mathrm{O}_{40}\right]\left(\mathrm{Na}-\mathrm{H}_{2} \mathrm{~W}_{12}\right)\right.$, $0.90 \mathrm{~g}(0.3 \mathrm{mmol}))$ was dissolved in $10 \mathrm{~mL}$ of ethanol/water $(1: 1(\mathrm{v} / \mathrm{v}))$, and insoluble solids were removed by filtration. To the obtained clear colorless filtrate was added an ethanol solution $(5 \mathrm{~mL})$ of MAImC $_{1}-\mathrm{I}(0.50 \mathrm{~g}, 1.55 \mathrm{mmol})$. Resulting colorless precipitates were filtered off, washed by water, and dried under ambient atmosphere to obtain colorless powder of 
MAImC $1-\mathrm{H}_{2} \mathrm{~W}_{12}(0.24 \mathrm{~g}$, yield: $17 \%)$. Colorless plate crystals of $\mathrm{MAImC}-\mathrm{H}_{2} \mathrm{~W}_{12}$ were grown from the washing solution of the MAImC $1-\mathrm{H}_{2} \mathrm{~W}_{12}$ precipitates. Some amounts of ethanol molecule seemed to remain in or onto the MAImC ${ }_{1}-\mathrm{H}_{2} \mathrm{~W}_{12}$ precipitates. Elemental analysis calcd (\%) for $\mathrm{C}_{68} \mathrm{H}_{116} \mathrm{~N}_{12} \mathrm{~W}_{12} \mathrm{O}_{56}$ : C, 19.42; $\mathrm{H}, 2.78 ; \mathrm{N}, 4.00$. Found: C, 20.12; H, 2.12; N, 3.88. IR, $v\left(\mathrm{KBr}\right.$ disk, $\left.\mathrm{cm}^{-1}\right)$ : 3138 (w), 2957 (w), 2924 (w), 2853 (w), 1725 (m), 1631 (s), $1578(\mathrm{w}), 1546(\mathrm{w}), 1445(\mathrm{w}), 1314(\mathrm{w}), 1289(\mathrm{w})$, $1156(\mathrm{w}), 1085(\mathrm{w}), 1031(\mathrm{w}), 933$ (m), 878 (m), 771 (s), $669(\mathrm{w}), 623(\mathrm{w}), 507(\mathrm{w})$.

\subsection{Synthesis of MAImC 1 -PMo ${ }_{12}$ hybrid crystal}

Dodecamolybdophosphoric acid $n$ hydrate $\left(\mathrm{H}_{3}\left[\mathrm{PMo}_{12} \mathrm{O}_{40}\right] \cdot n \mathrm{H}_{2} \mathrm{O}(\mathrm{H}-\mathrm{PMo} 12), 1.1 \mathrm{~g}(0.6 \mathrm{mmol})\right)$ was dissolved in $10 \mathrm{~mL}$ of ethanol. To the obtained clear yellow solution was added an ethanol solution $(5 \mathrm{~mL})$ of MAImC 1 -I (0.50 g, $1.55 \mathrm{mmol})$. Resulting dark-green precipitates were filtered off, washed by ethanol, and dried under ambient atmosphere to obtain dark-green powder of $\mathrm{MAImC}_{1}-\mathrm{PMo}_{12}(0.85 \mathrm{~g}$, yield: $56 \%)$. Yellow-green block crystals of $\mathrm{MAImC}_{1}-\mathrm{PMo}_{12}$ were grown from the hot acetonitrile $(10 \mathrm{~mL})$ or acetonitrile/ethanol $(10 \mathrm{~mL}, 1: 1$ $(\mathrm{v} / \mathrm{v}))$ solution of the MAImC $1-\mathrm{PMo}_{12}$ precipitates. Some amounts of ethanol molecule seemed to remain in or onto the MAImC ${ }_{1}-\mathrm{PMo}_{12}$ precipitates. Elemental analysis calcd (\%) for $\mathrm{C}_{32} \mathrm{H}_{51} \mathrm{~N}_{6} \mathrm{PMo}_{12} \mathrm{O}_{47}$ : C, 15.66; H, 2.09; N, 3.42 . Found: C, 15.95; H, 1.80; N, 3.41. IR, $v\left(\mathrm{KBr}\right.$ disk, $\left.\mathrm{cm}^{-1}\right)$ : $3152(\mathrm{w}), 3116(\mathrm{w}), 2960(\mathrm{w}), 2927(\mathrm{w}), 1720(\mathrm{~m}), 1636$ $(\mathrm{w}), 1561(\mathrm{w}), 1450(\mathrm{w}), 1316(\mathrm{w}), 1296(\mathrm{w}), 1164(\mathrm{~m})$, $1063(\mathrm{~m}), 957$ (s), $879(\mathrm{~m}), 801(\mathrm{~s}), 738(\mathrm{~m}), 649(\mathrm{w}), 621$ (w), $500(\mathrm{w}), 465(\mathrm{w}), 436(\mathrm{w}), 412(\mathrm{w})$.

\subsection{Crystal structure determination}

Single crystal X-ray diffraction measurements were performed with an ADSC Q210 CCD area detector by using a synchrotron radiation $(\lambda=0.63000-0.70000 \AA)$ at 2D beamline in Pohang Accelerator Laboratory (PAL, a synchrotron radiation facility in Pohang, Republic of Korea). The processing of diffraction images was performed with HKL3000 [41]. Absorption correction was done with PLATON [42] or HKL3000. The structures were solved by the direct methods (SHELXS97 or SHELXS(Version 2013/1)) [43], and refined by the full-matrix least-squares method on $F^{2}$ (SHELXL(Version 2014/7)) [43] with the usage of CrystalStructure software package [44].

\section{RESULTS AND DISCUSSION}

\subsection{Syntheses}

MAImC $_{1}$ hybrid crystals were synthesized by cation-exchange reaction in the solution of prescribed Keggin-type POM anions depicted in Fig. 1b. IR spectra of MAImC $1-\mathrm{H}_{2} \mathrm{~W}_{12}$ hybrid crystals (Fig. 2b) exhibited characteristic peaks for $\mathrm{MAImC}_{1}$ (methylene groups in $2800-3000 \mathrm{~cm}^{-1}$ and methacryloyl group in $1200-1800$ $\mathrm{cm}^{-1}$ ) together with the peaks of $\mathrm{H}_{2} \mathrm{~W}_{12}$ anion (400-1000 $\mathrm{cm}^{-1}$ ) as observed for the starting $\mathrm{Na}-\mathrm{H}_{2} \mathrm{~W}_{12}$ (Fig. 2a). This indicates successful hybridization of MAImC 1 and $\mathrm{H}_{2} \mathrm{~W}_{12}$. IR spectra of $\mathrm{MAImC}_{1}-\mathrm{PMo}_{12}$ (Fig. 2d) showed distinct peaks of PMo $12\left(400-1100 \mathrm{~cm}^{-1}\right)$ as shown in the starting $\mathrm{H}_{-\mathrm{PMo}}$ (Fig. 2c), demonstrating the successful hybridization of MAImC $\mathrm{M}_{1}$ and $\mathrm{PMo}_{12}$.

XRD patterns of MAImC $1-\mathrm{H}_{2} \mathrm{~W}_{12}$ and MAImC 1 -PMo12

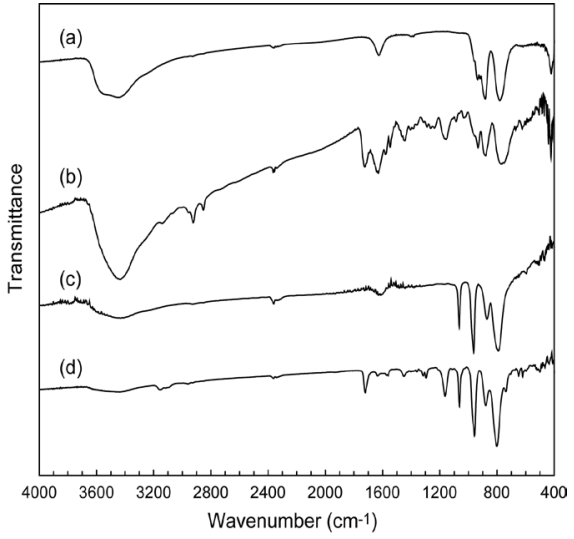

Fig. 2. IR spectra of (a) $\mathrm{Na}-\mathrm{H}_{2} \mathrm{~W}_{12}$, (b) $\mathrm{MAImC} \mathrm{Im}_{1}-\mathrm{H}_{2} \mathrm{~W}_{12}$, (c) $\mathrm{H}-\mathrm{PMo}_{12}$, and (d) MAImC $1-\mathrm{PMo}_{12}$.

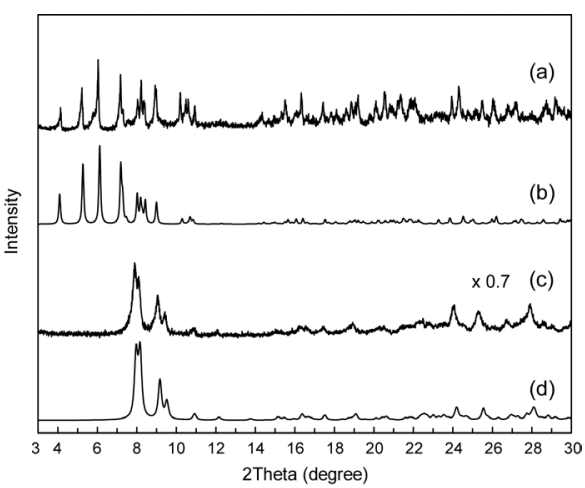

Fig. 3. Powder X-ray diffraction patterns of MAImC 1 -POM hybrid crystals. (a) Precipitate of MAImC $1-\mathrm{H}_{2} \mathrm{~W}_{12}$, (b) calculated pattern of MAImC ${ }_{1}-\mathrm{H}_{2} \mathrm{~W}_{12}$ using the result of single-crystal structure analysis, (c) precipitate of $\mathrm{MAImC}_{1}-\mathrm{PMo}_{12}$, and (d) calculated pattern of MAImC1-PMo12 using the result of single-crystal structure analysis.

hybrid crystals (Fig. 3a and 3c) were almost identical to the patterns calculated from the results of single crystal $\mathrm{X}$-ray analysis (Fig. $3 \mathrm{~b}$ and $3 \mathrm{~d}$ ). This demonstrates that both $\mathrm{MAImC}_{1}-\mathrm{H}_{2} \mathrm{~W}_{12}$ and $\mathrm{MAImC}_{1}-\mathrm{PMo}_{12}$ were precipitated as single phase with the same composition and structure as the single crystals. Differences in the peak intensity and position of the patterns may be due to the difference in the measurement temperature (powder: ambient temperature, single crystal: $100 \mathrm{~K}$ ).

\subsection{Structure of MAImC $\mathrm{I}_{1}-\mathrm{H}_{2} \mathrm{~W}_{12}$ hybrid crystal}

Single crystal X-ray analysis revealed the molecular structure of MAImC $1-\mathrm{H}_{2} \mathrm{~W}_{12}$ hybrid crystal [45], which was formulated to be $\left[\mathrm{MAImC}_{1}\right]_{6}\left[\mathrm{H}_{2} \mathrm{~W}_{12} \mathrm{O}_{40}\right]$. Fig. 4 shows asymmetric unit and crystal packing, which verified the presence of Keggin-type metatungstate anion of $\mathrm{H}_{2} \mathrm{~W}_{12}$ (Fig. 1b) [46-49] in $\mathrm{MAImC}_{1}-\mathrm{H}_{2} \mathrm{~W}_{12}$. The crystal contained no solvent molecule of crystallization.

All the counter cations of starting $\mathrm{Na}-\mathrm{H}_{2} \mathrm{~W}_{12}$ were exchanged, and six $\mathrm{MAImC}_{1}$ cations surrounded one $\mathrm{H}_{2} \mathrm{~W}_{12}$ (Fig. 4a). The imidazolium rings and $\mathrm{C}=\mathrm{C}$ bonds 
(a)

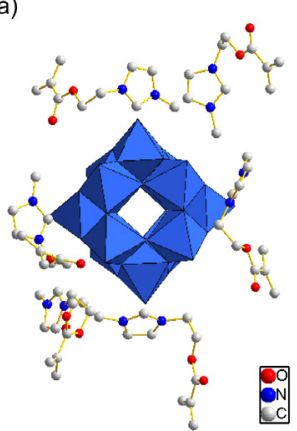

(b)

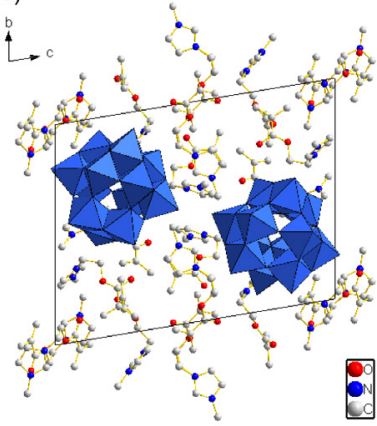

Fig. 4. Crystal structure of MAImC $1-\mathrm{H}_{2} \mathrm{~W}_{12}$. $\mathrm{H}$ atoms are omitted for clarity. (a) Asymmetric unit. (b) Packing diagram along $a$ axis.

(a)

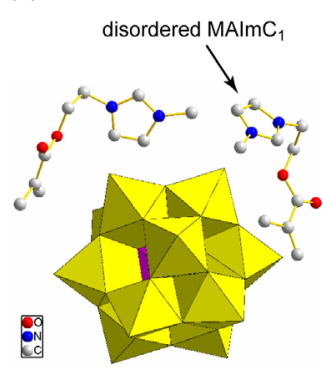

(b)

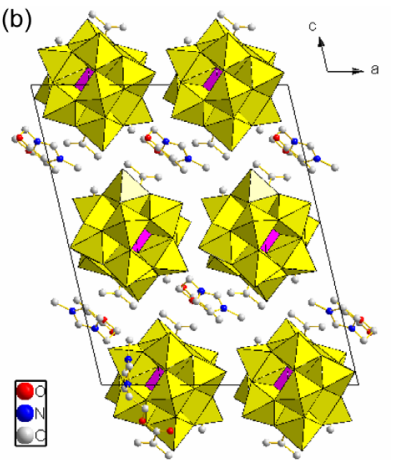

Fig. 5. Crystal structure of MAImC ${ }_{1}-\mathrm{PMo}_{12} . \mathrm{H}$ atoms are omitted for clarity. (a) Asymmetric unit. The PMo 12 anion is completed by symmetry operation $(0.5-x, 0.5-y$, $-z)$. (b) Packing diagram along $b$ axis. Selected disordered $\mathrm{MAImC}_{1}$ cations are omitted for clarity.

with $\pi$ electrons were located in the vicinity of each $\mathrm{H}_{2} \mathrm{~W}_{12}$ The $\mathrm{H}_{2} \mathrm{~W}_{12}$ anions surrounded by MAImC 1 may be reduced to colored species under photoexcitation $[17,50]$, and $\mathrm{MAImC} \mathrm{I}_{1}-\mathrm{H}_{2} \mathrm{~W}_{12}$ possibly behave as photochromic materials.

\subsection{Structure of $\mathrm{MAImC}_{1}-\mathrm{PMo}_{12}$ hybrid crystal}

Molecular structure and crystal packing of $\mathrm{MAImC}_{1}-\mathrm{PMo}_{12}$ were clarified as shown in Fig. 5 [51]. The chemical formula was $\left[\mathrm{MAImC}_{1}\right]_{3}\left[\mathrm{PMo}_{12} \mathrm{O}_{40}\right]$ without any crystallization solvent. The protons of starting H-PMo12 were fully exchanged, and three MAImC cations were associated with one $\mathrm{PMo}_{12}$. The asymmetric unit contained two MAImC 1 cations and a half of $\mathrm{PMo}_{12}$ anion (Fig. 5a). One crystallographically independent MAImC $_{1}$ with a site occupancy of 0.5 was disordered around 2-fold axis. The $\mathrm{PMo}_{12}$ anion was located on the inversion center, and exhibited a common type of disorder for Keggin anion [52]. MAImC $1-\mathrm{PMo}_{12}$ was isostructural to that of hybrid crystal comprising $\mathrm{MAImC}_{1}$ and $\mathrm{PW}_{12}$ anion having the same charge (3-) as PMo12 [38].

Each PMo12 anion was isolated and surrounded by $\mathrm{MAImC}_{1}$ in the yellow-green crystals (Fig. 5b). The crystal color indicates that slight amount of $\mathrm{PMo}_{12}$ anions were reduced to dark blue-colored species $[13,17,25]$ in

most non-reduced yellow $\mathrm{PMo}_{12}$ anions. This may be because the $\mathrm{PMo}_{12}$ anion is more easily reduced than $\mathrm{H}_{2} \mathrm{~W}_{12}[13,18]$. The MAImC1-PMo12 hybrid crystal could be considered as a weak charge-transfer salt [53].

\section{CONCLUSIONS}

Polymerizable ionic-liquid (MAImC ${ }_{1}$ ) was firstly hybridized with Keggin-type polyoxometaltes of metatungstate $\left(\mathrm{H}_{2} \mathrm{~W}_{12}\right)$ and dodecatungstophosphate $\left(\mathrm{PMo}_{12}\right)$ as single crystals. Their molecular and crystal structures were clearly revealed that each $\mathrm{H}_{2} \mathrm{~W}_{12}$ or $\mathrm{PMo}_{12}$ anion was isolated by the $\pi$ electron-rich $\mathrm{MAImC}_{1}$ cations. The charge-transfer from MAImC 1 to $\mathrm{H}_{2} \mathrm{~W}_{12}$ or $\mathrm{PMo}_{12}$ may be result in the emergence of photochromic property. In principle, these hybrid crystals can be polymerized derived from the polymerizable $\mathrm{MAImC}_{1}$ cation, which would pave a way to another class of inorganic-organic hybrid functional polymers.

\section{ACKNOWLEDGMENTS}

This work was partly supported by JSPS KAKENHI Grant Number JP26410245, and by Research and Study Project of Tokai University Educational System General Research Organization. X-ray diffraction measurements with synchrotron radiation were performed at the Pohang Accelerator Laboratory (2D Beamline) supported by Pohang University of Science and Technology (POSTECH).

\section{REFERENCES}

[1] T. L. Greaves and C. J. Drummond, Chem. Soc. Rev., 37, 1709-1726 (2008).

[2] M. Armand, F. Endres, D. R. MacFarlane, H. Ohno, and B. Scrosati, Nature Mater., 8, 621-629 (2009).

[3] T. Kato, J. Uchida, T. Ichikawa, and T. Sakamoto, Angew. Chem. Int. Ed., 57, 4355-4371 (2018).

[4] N. Nishimura and H. Ohno, Polymer, 55, 3289-3297 (2014).

[5] M. Watanabe, M. L. Thomas, S. Zhang, K. Ueno, T. Yasuda, and K. Dokko, Chem. Rev., 117, 7190-7239 (2017).

[6] W. Qian, J. Texter, and F. Yan, Chem. Soc. Rev., 46, 1124-1159 (2017).

[7] T. Welton, Chem. Rev., 99, 2071-2083 (1999).

[8] Y. Nagase, B. Suleimenova, C. Umeda, K. Taira, T. Oda, S. Suzuki, Y. Okamura, and S. Koguchi, Polymer, 135, 142-153 (2018).

[9] E. Coronado and C. J. Gómez-García, Chem. Rev., 98, 273-296 (1998).

[10] E. Coronado, C. Giménez-Saiz, and C. J. Gómez-García, Coord. Chem. Rev., 249, 1776-1796 (2005).

[11] P. He, S. Shimano, K. Salikolimi, T. Isoshima, Y. Kakefuda, T. Mori, Y. Taguchi, Y. Ito, and M. Kawamoto, ACS Appl. Mater. Interfaces, 11, 4211-4218 (2019).

[12] M. Liu, Y. Ishida, Y. Ebina, T. Sasaki, T. Hikima, M. Takata, and T. Aida, Nature, 517, 68-72 (2015).

[13] M. T. Pope, "Heteropoly and Isopoly Oxometalates", Springer, Berlin (1983).

[14] Y.-F. Song, D.-L. Long, C. Ritchie, and L. Cronin, Chem. Rec., 11, 158-171 (2011).

[15] A. Misra, K. Kozma, C. Streb, and M. Nyman, Angew. Chem. Int. Ed., 59, 596-612 (2020).

[16] A. Proust, B. Matt, R. Villanneau, G. Guillemot, P. 
Gouzerh, and G. Izzet, Chem. Soc. Rev., 41, 7605-7622 (2012).

[17] T. Yamase, Chem. Rev., 98, 307-325 (1998).

[18] M. Sadakane and E. Steckhan, Chem. Rev., 98, 219-237 (1998).

[19] W. Qi and L. Wu, Polym. Int., 58, 1217-1225 (2009).

[20] P. Gomez-Romero, Adv. Mater., 13, 163-174 (2001).

[21] A. M. Herring, J. Macromol. Sci. Part C, 46, 245-296 (2006).

[22] I. Honma and M. Yamada, Bull. Chem. Soc. Jpn., 80, 2110-2123 (2007).

[23] M. Kourasi, R. G. A. Wills, A. A. Shah, and F. C. Walsh, Electrochim. Acta, 127, 454-466 (2014).

[24] S. Herrmann, C. Ritchie, and C. Streb, Dalton Trans., 44, 7092-7104 (2015)

[25] T. Okuhara, N. Mizuno, and M. Misono, Adv. Catal., 41, 113-252 (1996).

[26] O. Nakamura, T. Kodama, I. Ogino, and Y. Miyake, Chem. Lett., 8, 17-18 (1979).

[27] T. Kukino, R. Kikuchi, T. Takeguchi, T. Matsui, and K. Eguchi, Solid State Ionics, 176, 1845-1848 (2005).

[28] A. Klaiber, S. Landsmann, T. Löffler, and S. Polarz, New J. Chem., 40, 919-922 (2016).

[29] A. B. Bourlinos, K. Raman, R. Herrera, Q. Zhang, L. A. Archer, and E. P. Giannelis, J. Am. Chem. Soc., 126, 15358-15359 (2004).

[30] Y. Leng, J. Wang, D. Zhu, X. Ren, H. Ge, and L. Shen, Angew. Chem. Int. Ed., 48, $168-171$ (2009).

[31] C. Gao, G. Chen, X. Wang, J. Li, Y. Zhou, and J. Wang, Chem. Commun., 51, 4969-4972 (2015).

[32] X. Wu, X. Tong, Q. Wu, H. Ding, and W. Yan, $J$. Mater. Chem. A, 2, 5780-5784 (2014).

[33] S.-Y. Oh, T. Yoshida, G. Kawamura, H. Muto, M. Sakai, and A. Matsuda, J. Mater. Chem., 20, 6359-6366 (2010).

[34] M. Tsuboi, M. Hibino, N. Mizuno, and S. Uchida, $J$. Solid State Chem., 234, 9-14 (2016).

[35] L. Zhang, T. Cui, X. Cao, C. Zhao, Q. Chen, L. Wu, and H. Li, Angew. Chem. Int. Ed., 56, 9013 -9017 (2017).

[36] T. Hasegawa, K. Shimizu, H. Seki, H. Murakami, S. Yoshida, K. Yoza, and K. Nomiya, Inorg. Chem. Commun., 10, 1140-1144 (2007).

[37] T. Hasegawa, H. Murakami, K. Shimizu, Y. Kasahara, S. Yoshida, T. Kurashina, H. Seki, and K. Nomiya, Inorg. Chim. Acta, 361, 1385-1394 (2007).

[38] T. Ito, S. Otobe, T. Oda, T. Kojima, S. Ono, M. Watanabe, Y. Kiyota, T. Misawa, S. Koguchi, M. Higuchi, M. Kawano, and Y. Nagase, Polymers, 9, 290 (2017).

[39] J. Kobayashi, T. Misawa, C. Umeda, T. Isono, S. Ono, H. Naruke, Y. Okamura, S. Koguchi, M. Higuchi, Y. Nagase, and T. Ito, CrystEngComm, 21, 629-636 (2019).

[40] T. Ito, Y. Kiyota, T. Oda, M. Watanabe, S. Ono, Y. Oda, T. Misawa, T. Isono, S. Otobe, Y. Okamura, S. Koguchi, M. Higuchi, and Y. Nagase, , Trans. Mat. Res. Soc. Japan, 44, 101-107 (2019).

[41] W. Minor, M. Cymborowski, Z. Otwinowski, and M. Chruszcz, Acta Crystallogr., Sect. D, 62, 859-866 (2006).

[42] A. L. Spek, Acta Crystallogr., Sect. D, 65, 148-155 (2009).

[43] G. M. Sheldrick, Acta Crystallogr., Sect A, 64, 112-122 (2008).

[44] CrystalStructure 4.3, Rigaku Corporation, Tokyo (2018).

[45] Crystal data for MAImC $1-\mathrm{H}_{2} \mathrm{~W}_{12}: \mathrm{C}_{60} \mathrm{H}_{90} \mathrm{~N}_{12} \mathrm{~W}_{12} \mathrm{O}_{52}$,
$M_{\mathrm{r}}=4017.63$, triclinic, space group $P-1$ (No. 2), $a=$ 12.87150(10), $b=18.00810(10), c=21.9329(2) \AA, \alpha=$ 79.5980(10), $\beta=85.4490(10), \gamma=70.5310(10){ }^{\circ}, V=$ 4713.39(7) $\AA^{3}, Z=2, T=100 \mathrm{~K} .96321$ reflections measured, 27398 reflections independent $\left(R_{\text {int }}=0.0492\right)$. No. of parameters 1254, $R_{1}=0.0504(I>2 \sigma(I))$, and $w R_{2}$ $=0.1381$ (all data). CCDC 2044470 .

[46] M. Asami, H. Ichida, and Y. Sasaki, Acta Crystallogr., Sect C, 40, 35-37 (1984).

[47] L. Seguin, B. Gerand, and G. Nowogrocki, Eur. J. Solid State Inorg. Chem., 32, 181-194 (1995).

[48] P. Zavalij, J. Guo, M. S. Whittingham, R. A. Jacobson, V. Pecharsky, C. K. Bucher, and S.-J. Hwu, J. Solid State Chem., 123, 83-92 (1996).

[49] J. H. Son, Y.-U. Kwon, and O. H. Han, Inorg. Chem., 42, 4153-4159 (2003).

[50] Y. Jeannin, J. P. Launay, and M. A. Seid Sedjadi, Inorg. Chem., 19, 2933-2935 (1980).

[51] Crystal data for MAImC $1-\mathrm{PMo}_{12}: \mathrm{C}_{30} \mathrm{H}_{45} \mathrm{~N}_{6} \mathrm{PMo}_{12} \mathrm{O}_{46}$, $M_{\mathrm{r}}=2407.95$, monoclinic, space group $C 2 / c$ (No. 15), $a=$ $19.0770(2), b=14.5490(2), c=22.7970(3) \AA, \beta=$ 103.2765(4) ${ }^{\circ}, V=6158.23(13) \AA^{3}, Z=4, T=100 \mathrm{~K}$. 89085 reflections measured, 7789 reflections independent $\left(R_{\text {int }}=0.0600\right)$. No. of parameters $495, R_{1}=0.0978(I>$ $2 \sigma(I))$, and $w R_{2}=0.2104$ (all data). CCDC 2044471.

[52] H. T. Evans, Jr. and M. T. Pope, M. T. Inorg. Chem., 23, 501-504 (1984).

[53] D. Attanasio, M. Bonamico, V. Fares, P. Imperatori, and L. Suber, J. Chem. Soc., Dalton Trans., 3221-3228 (1990).

(Received November 18, 2020; Accepted December 18, 2020; Published Online March 1, 2021) 